\title{
Mechanisms of Oxidase and SOD-like Activities of Gold, Silver, Platinum, and Palladium, and Their Alloys: A General Way to the Activation of Molecular Oxygen
}

Contents

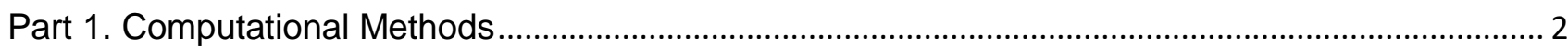

Part 2. Oxidase-like Activities Investigation for Four Metals Pd, Pt, Ag, and Au................................ 3

Part 3. Adsorption Sites on $\mathrm{Au}_{4-\mathrm{x}} \mathrm{M}_{x}(x=1,2,3 ; \mathrm{M}=\mathrm{Pd}, \mathrm{Pt}, \mathrm{Ag})$ Alloys .............................................. 4

Part 4. Energetically Favorable Adsorption Sites and Bader Charges of Oxygen Adsorption on Alloys 4

Part 5. Adsorption Energies for Initial Structures (IS), Transition States (TS), and Final Structures (FS) of $\mathrm{O}_{2}$ Adsorption on Alloys with Different Spin States.

Part 6. Structures of $\mathrm{Au}, \mathrm{Ag}, \mathrm{Pd}$, and Pt Displaying SOD-like Activities ............................................ 5

Part 7. Experimental Test of Oxidase-like Activities of Metals and Their Alloys ................................ 6

Part 8. Potential Energy Surface for $\mathrm{O}_{2}$ Adsorption and Dissociation on $\mathrm{Pd}(100)$ Facet................... 11

Part 9. Energies of Optimized Structures. ...................................................................................... 11 


\section{Part 1. Computational Methods}

Table S1. Energies of $\mathrm{O}_{2}$ Adsorbed on Metal Facets before and after Dissociation ( $E_{\mathrm{O} 2}$ and $E_{20}$ ), and the Reaction Energies $\left(E_{\mathrm{O} 2}-E_{2 \mathrm{O}}\right.$ ), Calculated with Different Density Functionals

\begin{tabular}{ccccc}
\hline Metal & & PBE $(\mathrm{eV})$ & RPBE $^{a}(\mathrm{eV})$ & revPBE $^{b}(\mathrm{eV})$ \\
\hline \multirow{3}{*}{$\mathrm{Pd}(111)$} & $E_{\mathrm{O} 2}$ & $186.953^{c}$ & $180.972^{d}$ & $186.943^{d}$ \\
& $E_{2 \mathrm{O}}$ & $188.301^{c}$ & $182.150^{d}$ & $188.307^{d}$ \\
& $E_{\mathrm{O} 2}-E_{2 \mathrm{O}}$ & 1.348 & 1.178 & 1.364 \\
\hline $\mathrm{Pt}(111)$ & $E_{\mathrm{O} 2}$ & $218.313^{c}$ & $211.485^{d}$ & $218.314^{d}$ \\
& $E_{2 \mathrm{O}}$ & $219.561^{c}$ & $212.546^{d}$ & $219.550^{d}$ \\
& $E_{\mathrm{O} 2}-E_{2 \mathrm{O}}$ & 1.248 & 1.061 & 1.236 \\
$\mathrm{Ag}(111)$ & $E_{\mathrm{O} 2}$ & $106.129^{c}$ & $102.322^{d}$ & $106.129^{d}$ \\
& $E_{2 \mathrm{O}}$ & $105.968^{c}$ & $-101.870^{d}$ & $105.968^{d}$ \\
& $E_{\mathrm{O} 2}-E_{2 \mathrm{O}}$ & 0.161 & 0.452 & 0.161 \\
\hline $\mathrm{Au}(111)$ & $E_{\mathrm{O} 2}$ & $122.093^{c}$ & $117.304^{d}$ & $121.826^{d}$ \\
& $E_{2 \mathrm{O}}$ & $121.410^{c}$ & $116.550^{d}$ & $121.408^{d}$ \\
& $E_{\mathrm{O} 2}-E_{2 \mathrm{O}}$ & 0.683 & 0.754 & 0.418 \\
\hline
\end{tabular}

${ }^{a}$ Invoked by setting "GGA=RP". ' Invoked by setting "GGA=RE". 'Obtained by structural optimizations with spin polarized DFT. ${ }^{d}$ Obtained by single-point energy calculations on the basis of the optimized structures.

To test the performance of PBE method, we did single-point energy calculations for the dissociative adsorption of ${ }^{3} \mathrm{O}_{2}$ on metal surfaces using two improved versions of PBE functional, RPBE and revPBE. According to Table $S 1$, the energies ( $E_{\mathrm{O} 2}$ and $\left.E_{2 \mathrm{O}}\right)$ and reaction energies $\left(E_{\mathrm{O} 2}-E_{2 \mathrm{O}}\right)$ by PBE are very close to those by revPBE. Most of the differences are smaller than $0.02 \mathrm{eV}$, except for $E_{\mathrm{O} 2}-E_{2 \mathrm{O}}$ of $\mathrm{Au}(111)$, which is $0.265 \mathrm{eV}$. By contrast, $E_{\mathrm{O} 2}$ and $E_{2 \mathrm{O}}$ by PBE differ a lot from those by RPBE. However, the reaction energies $\left(E_{\mathrm{O} 2}-E_{2 \mathrm{O}}\right)$ by $\mathrm{PBE}$ and $\mathrm{RPBE}$, which are of interest in this work, are also close and smaller than $0.3 \mathrm{eV}$. Importantly, three DFT methods predict the same orders for the reaction energies, $\operatorname{Pd}(111)<\operatorname{Pt}(111)<\operatorname{Ag}(111)<\mathrm{Au}(111)$. Therefore, PBE is used for all calculation in this work.

We also performed geometry optimizations using a tighter convergence criterion of $-0.002 \mathrm{eV} / \AA$ for the structures involved in the dissociative adsorption of $\mathrm{O}_{2}$ on $\mathrm{Au}(111)$ (Table S2). The results are given in Table S2. For comparison, the energies obtained with a convergence criterion of $-0.02 \mathrm{eV} / \AA$ were also given. The energy difference for ${ }^{3} \mathrm{O}_{2}$ initial structure is $0.0373 \mathrm{eV}$; that for ${ }^{3} \mathrm{O}_{2}$ transition state is $0.0924 \mathrm{eV}$. The other four differences are smaller than $0.0002 \mathrm{eV}$. Therefore, the criterion of $-0.02 \mathrm{eV} / \AA$ should be acceptable. Because the criterion of -0.02 is computationally much less demanding, we used this criterion for all geometry optimizations in this work.

Table S2. Energies (unit: eV) of Species Involved in the Dissociative Adsorption of ${ }^{3} \mathrm{O}_{2}$ and ${ }^{1} \mathrm{O}_{2}$ on $\mathrm{Au}(111)$ Facet with Two Different Force Convergence Criteria

\begin{tabular}{ccccc}
\hline & $\begin{array}{c}\text { Convergence } \\
\text { Criteria }(\mathrm{eV} / \AA)\end{array}$ & Initial structure & Transition state & Dissociated structure \\
\hline${ }^{3} \mathrm{O}_{2}{ }^{a}$ & -0.02 & -122.0951 & -119.9848 & -121.4078 \\
& -0.002 & -122.1324 & -119.8924 & -121.4080 \\
${ }^{1} \mathrm{O}_{2}{ }^{b}$ & -0.02 & -121.3608 & -119.9426 & -121.1928 \\
& -0.002 & -121.3610 & -119.9430 & -121.1929 \\
\hline
\end{tabular}

${ }^{a}$ With spin-polarized DFT. ${ }^{6}$ With spin-unpolarized DFT. 
Part 2. Oxidase-like Activities Investigation for Four Metals Pd, Pt, Ag, and Au

Table S3. O-O Distances ( $\left.d_{0-0}\right)$, Net Bader Atomic Charges and Magnetic Moments $(\mu)$ of the Initial $\mathrm{O}_{2}$ Adsorbates at High and Low Spin States

\begin{tabular}{cccccc}
\hline & & $d_{\mathrm{O}-\mathrm{o}}(\AA)$ & charge $(e)^{a}$ & $\mu\left(\mu_{\mathrm{B}}\right)^{b}$ & energy $(\mathrm{eV})$ \\
\hline $\mathrm{Pd}(111)$ & High & 1.36 & $-0.57^{c}$ & $0.05^{c}$ & $-186.953^{c}$ \\
& Low & 1.37 & -0.55 & 0 & \\
$\mathrm{Pt}(111)$ & High & 1.34 & $-0.09^{c}$ & $1.52^{c}$ & $-218.313^{c}$ \\
& Low & 1.36 & -0.48 & 0 & $-106.129^{c}$ \\
$\mathrm{Ag}(111)$ & High & 1.27 & $-0.29^{c}$ & $1.33^{c}$ & \\
& Low & 1.33 & -0.55 & 0 & $-122.093^{c}$ \\
$\mathrm{Au}(111)$ & High & 1.25 & $-0.09^{c}$ & $1.62^{c}$ & \\
& Low & 1.27 & -0.24 & 0 & $-110.217^{c}$ \\
$\mathrm{Au}(110)$ & High & 1.41 & $-0.67^{c}$ & $0.41^{c}$ & \\
& Low & 1.34 & -0.47 & 0 & $-128.186^{c}$ \\
$\mathrm{Au}(211)$ & High & 1.29 & $-0.30^{c}$ & $1.15^{c}$ & \\
& Low & 1.37 & -0.48 & 0 &
\end{tabular}

${ }^{a}$ Sum of net Bader atomic charges of both $\mathrm{O}$ atoms in the $\mathrm{O}_{2}$ unit. ${ }^{b}$ Sum of magnetic moments of both $\mathrm{O}$ atoms in the $\mathrm{O}_{2}$ unit. ${ }^{c}$ Obtained by structural optimizations with the spin polarized PBE and with the system magnetic moments fully relaxed.

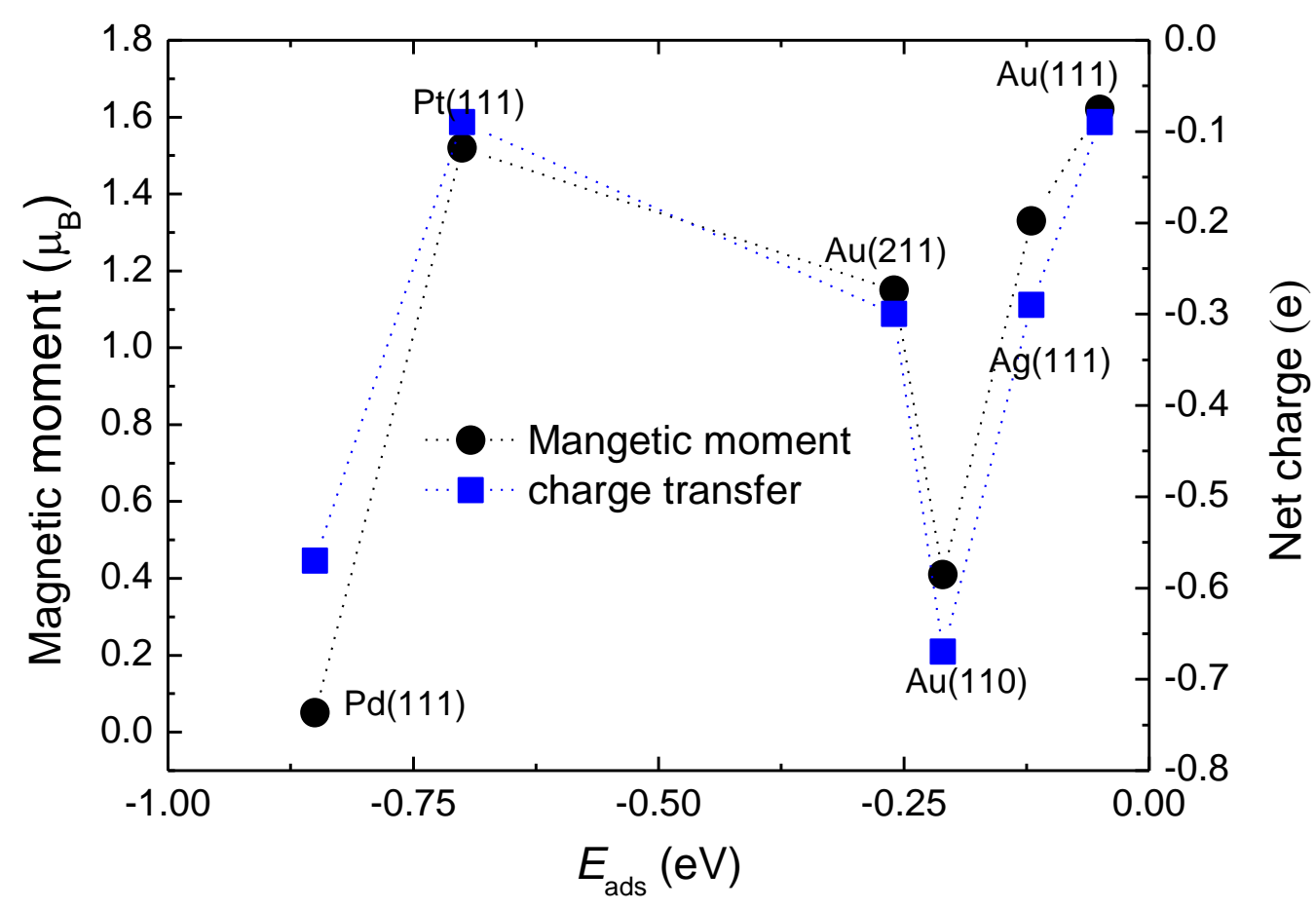

Figure S1. Magnetic moments and net charges of $\mathrm{O}_{2}$ adsorbed on metal surfaces with respect to the adsorption energies. 
To investigate the possible correlations among $E_{\text {ads, }}$, net charges, and magnetic moments of $\mathrm{O}_{2}$ on metal surfaces, Figure S1 was plotted. As shown in Figure S1, the charges and magnetic moments are well correlated. This is rational because the decrease of $\mathrm{O}_{2}$ magnetic moment is cause by the filling of the antibonding $\pi^{*}$ orbital of $\mathrm{O}_{2}$ by electrons transferred from metals. However, no straightforward correlation appears for $E_{\text {ads }}$ and net charges. This may indicate that $E_{\text {ads }}$ consists of other important components besides electrostatic interaction caused by charge separation.

Part 3. Adsorption Sites on $\mathrm{Au}_{4-x} \mathrm{M}_{x}(x=1,2,3 ; \mathrm{M}=\mathrm{Pd}, \mathrm{Pt}, \mathrm{Ag})$ Alloys

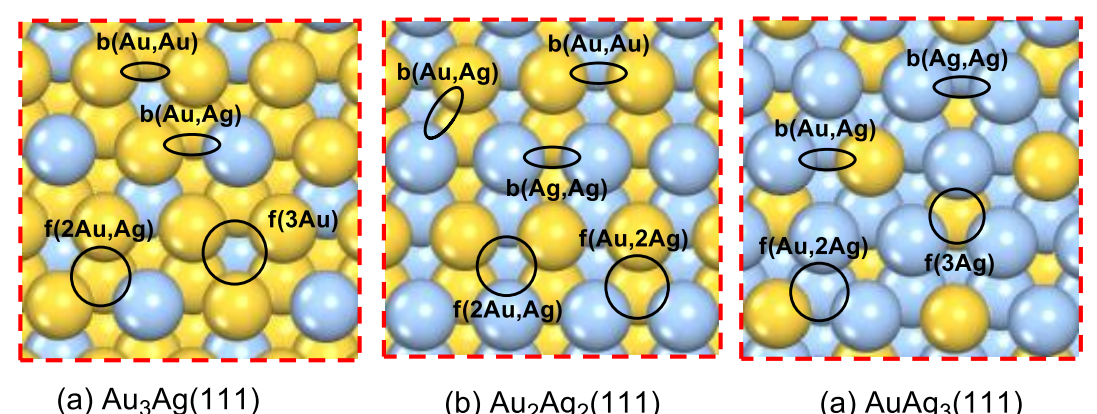

Figure S2. The adsorption sites for oxygen on (111) facets of $\mathrm{Au}_{3} \mathrm{Ag}, \mathrm{Au}_{2} \mathrm{Ag}_{2}$, and $\mathrm{AuAg}_{3}$.

Part 4. Energetically Favorable Adsorption Sites and Bader Charges of Oxygen Adsorption on Alloys

Table S4. Energetically Favorable Adsorption Sites, O-O Distances (do-o), Net Bader Atomic Charges of the Initial $\mathrm{O}_{2}$ Adsorbates at Low Spin States

\begin{tabular}{cccc}
\hline & site & $d_{\mathrm{o}-\mathrm{o}}(\AA)$ & charge $(\mathrm{e})^{a}$ \\
\hline $\mathrm{Au}_{3} \mathrm{Ag}$ & $\mathrm{f}(2 \mathrm{Au}, \mathrm{Ag})$ & 1.40 & -0.75 \\
$\mathrm{Au}_{2} \mathrm{Ag}_{2}$ & $\mathrm{f}(2 \mathrm{Ag}, \mathrm{Au})$ & 1.39 & -0.76 \\
$\mathrm{AuAg}_{3}$ & $\mathrm{f}(3 \mathrm{Ag})$ & 1.42 & -0.81 \\
$\mathrm{Au}_{3} \mathrm{Pd}$ & $\mathrm{b}(\mathrm{Au}, \mathrm{Pd})$ & 1.32 & -0.49 \\
$\mathrm{Au}_{2} \mathrm{Pd}_{2}$ & $b(\mathrm{Pd}, \mathrm{Pd})$ & 1.35 & -0.51 \\
$\mathrm{AuPd}_{3}$ & $b(\mathrm{Pd}, \mathrm{Pd})$ & 1.34 & -0.50 \\
$\mathrm{Au}_{3} \mathrm{Pt}$ & $\mathrm{b}(\mathrm{Au}, \mathrm{Pt})$ & 1.34 & -0.51 \\
$\mathrm{Au}_{2} \mathrm{Pt}_{2}$ & $b(\mathrm{Pt}, \mathrm{Pt})$ & 1.38 & -0.55 \\
$\mathrm{AuPt}_{3}$ & $\mathrm{~b}(\mathrm{Pt}, \mathrm{Pt})$ & 1.39 & -0.53 \\
\hline
\end{tabular}

${ }^{a}$ Sum of net Bader atomic charges of both $\mathrm{O}$ atoms in the $\mathrm{O}_{2}$ unit. 
Part 5. Adsorption Energies for Initial Structures (IS), Transition States (TS), and Final Structures (FS) of $\mathrm{O}_{2}$ Adsorption on Alloys with Different Spin States

Table S5. Adsorption Energies of IS, TS, and FS, and Activation Energy Barriers of Rate-Determining Steps $\left(E_{\text {act }}\right)$ for $\mathrm{O}_{2}$ Dissociative Adsorption on Different Alloy Surfaces at High and Low Spin States (Unit: eV)

\begin{tabular}{lcclll}
\hline & & IS & FS & TS & $E_{\text {act }}$ \\
\hline $\mathrm{Au}_{3} \mathrm{Ag}_{1}(111)$ & high & -0.09 & -1.47 & 0.88 & 0.97 \\
& low & -0.02 & -1.07 & 0.89 & 0.91 \\
$\mathrm{Au}_{2} \mathrm{Ag}_{2}(111)$ & high & -0.25 & -1.28 & 0.91 & 1.16 \\
& low & -0.24 & -1.20 & 0.68 & 0.92 \\
$\mathrm{Au}_{1} \mathrm{Ag}_{3}(111)$ & high & -0.30 & -1.59 & 0.49 & 0.79 \\
& low & -0.48 & -1.59 & 0.30 & 0.78 \\
$\mathrm{Au}_{3} \mathrm{Pd}_{1}(111)$ & high & -0.07 & -0.01 & 1.77 & 1.84 \\
& low & 0.43 & 0.72 & 1.89 & 1.46 \\
$\mathrm{Au}_{2} \mathrm{Pd}_{2}(111)$ & high & -0.65 & 0.12 & 1.08 & 1.73 \\
& low & -0.64 & 0.18 & 1.03 & 1.67 \\
$\mathrm{Au}_{1} \mathrm{Pd}_{3}(111)$ & high & -1.47 & -0.95 & 0.20 & 1.67 \\
& low & -0.59 & -0.49 & 0.95 & 1.54 \\
$\mathrm{Au}_{3} \mathrm{Pt}_{1}(111)$ & high & -0.24 & -0.06 & 1.24 & 1.48 \\
& low & 0.21 & 0.03 & 1.24 & 1.03 \\
$\mathrm{Au}_{2} \mathrm{Pt}_{2}(111)$ & high & -0.84 & -0.04 & 0.38 & 1.22 \\
& low & -0.83 & -0.04 & 0.34 & 1.17 \\
$\mathrm{Au}_{1} \mathrm{Pt}_{3}(111)$ & high & -0.78 & -1.07 & 0.21 & 0.99 \\
& low & -0.75 & -1.07 & 0.33 & 1.08 \\
\hline
\end{tabular}

\section{Part 6. Structures of $\mathrm{Au}, \mathrm{Ag}, \mathrm{Pd}$, and Pt Displaying SOD-like Activities}

Figure S3 shows the structures and adsorption energies $\left(E_{\text {ads }} \mathrm{s}\right)$ for species involved in the rearrangements of $\mathrm{HO}_{2} \cdot$ radicals on metal surfaces $\mathrm{Ag}(111), \mathrm{Pd}(111), \mathrm{Au}(211), \mathrm{Ag}(211), \mathrm{Pd}(211)$, and $\mathrm{Pt}(211)$. The top figures are respectively for the initial structures of the adsorbed $\mathrm{HO}_{2} \cdot$; the bottom ones are for the products of the rearrangements, i.e., $\mathrm{H}_{2} \mathrm{O}_{2}{ }^{*}+\mathrm{O}_{2}{ }^{*}$. Similar to the cases of $\mathrm{Au}(111)$ and $\mathrm{Pt}(111)$, all the $E_{\text {ads's }}$ are lower than $-1.0 \mathrm{eV}$. This suggests that $\mathrm{HO}_{2} \cdot$ free radicals derived from $\mathrm{O}_{2}{ }^{-}($Eq. 3 ) can easily bind to the metals, which then possibly undergo rearrangements to afford $\mathrm{H}_{2} \mathrm{O}_{2}{ }^{*}$ and $\mathrm{O}_{2}{ }^{*}$. This accounts for the SOD-like activities of the metals. 


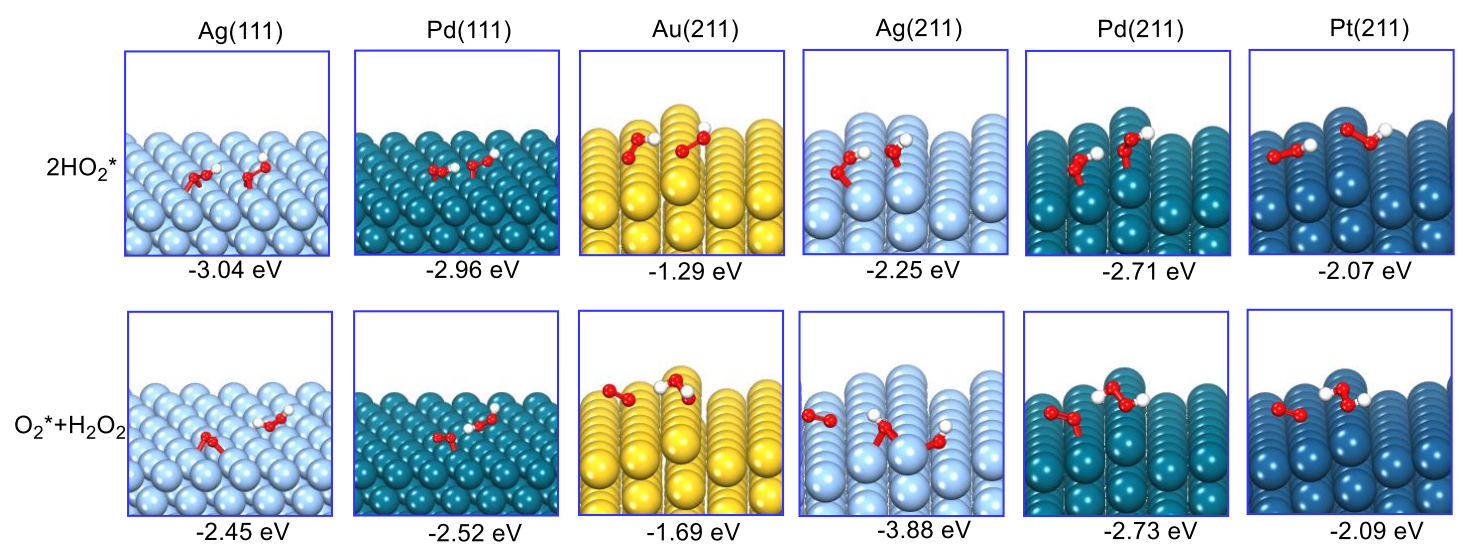

Figure S3. Structures and adsorption energies for species involved in the rearrangement of $\mathrm{HO}_{2}$. on different metal surfaces; each energy is relative to the sum of energies two $\mathrm{HO}_{2}$. free radicals and the clean metal surface.

Part 7. Experimental Test of Oxidase-like Activities of Metals and Their Alloys

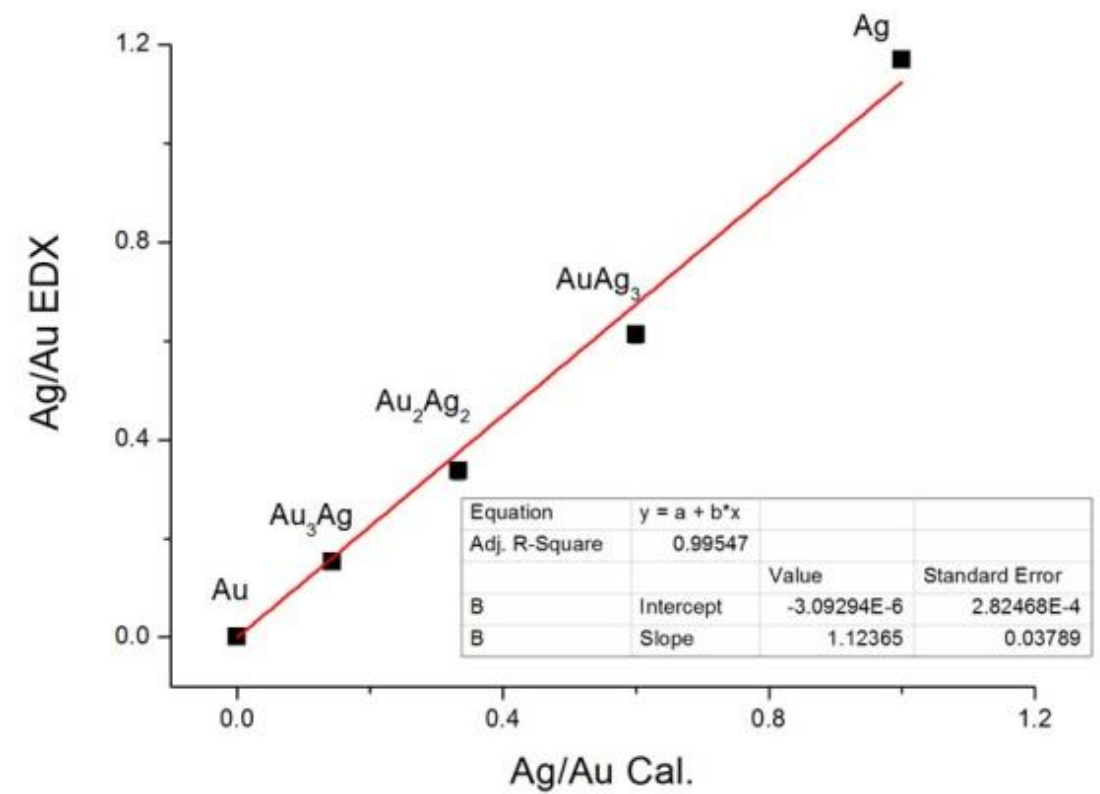

Figure S4. Measured Ag/Au ratio from Energy dispersive X-ray spectroscopy (EDX) analysis vs. calculated Ag/Au ratio in order to obtain corresponding shell composition.

Table S6. The EDX Element Analysis Results of Au@M Nanostructures

\begin{tabular}{|l|c|c|c|c|c|c|}
\hline & $\mathrm{Au} @ \mathrm{Au}_{3} \mathrm{Ag}$ & $\mathrm{Au@Au}_{2} \mathrm{Ag}_{2}$ & $\mathrm{Au} @ \mathrm{AuAg}_{3}$ & $\mathrm{Au} @ \mathrm{Ag}$ & $\mathrm{Au@Pd}$ & $\mathrm{Au@Pt}$ \\
\hline $\mathrm{M} / \mathrm{Au}$ (Cal.) & 0.14 & 0.33 & 0.6 & 1 & 1 & 1 \\
\hline $\mathrm{M} / \mathrm{Au}$ (EDX) & $0.15 \pm 0.01$ & $0.34 \pm 0.02$ & $0.61 \pm 0.02$ & $1.2 \pm 0.02$ & $1.0 \pm 0.02$ & $1.14 \pm 0.05$ \\
\hline
\end{tabular}




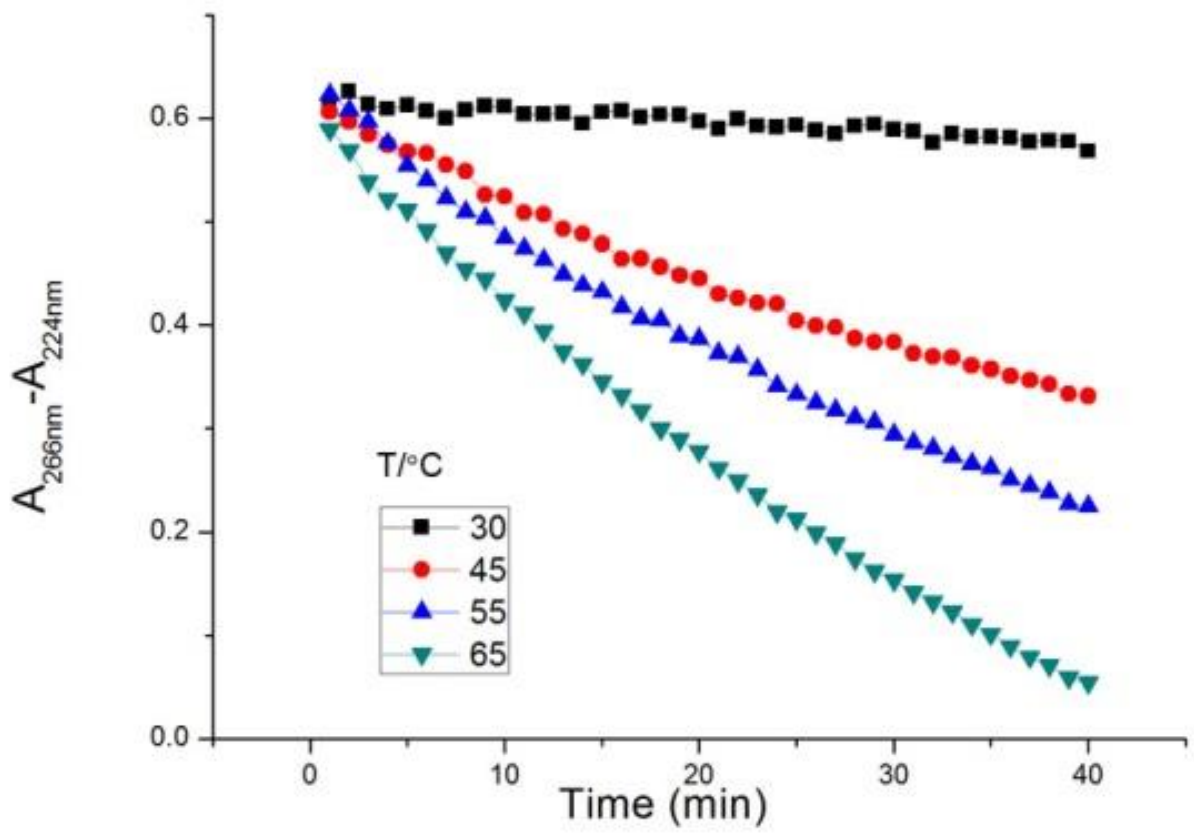

Figure S5. Thermal activation of sodium ascorbate ( $\mathrm{NaA})$ oxidation by increasing reaction temperature using Au@AuAg $\mathrm{NRs}_{3}$ as example. 


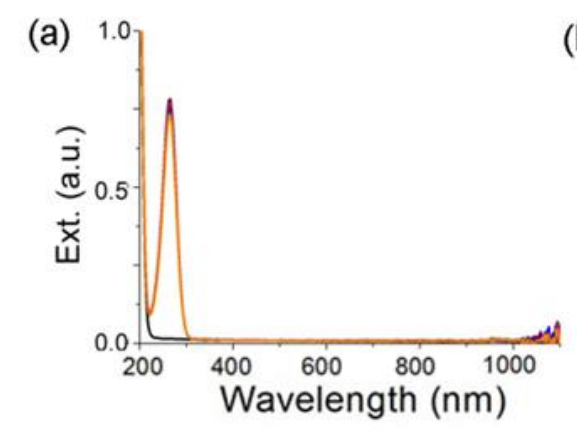

(d)

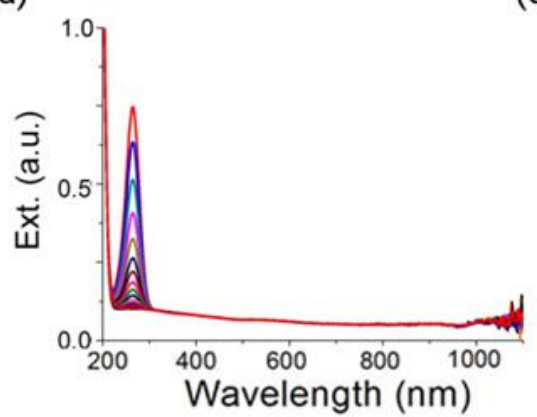

(g)

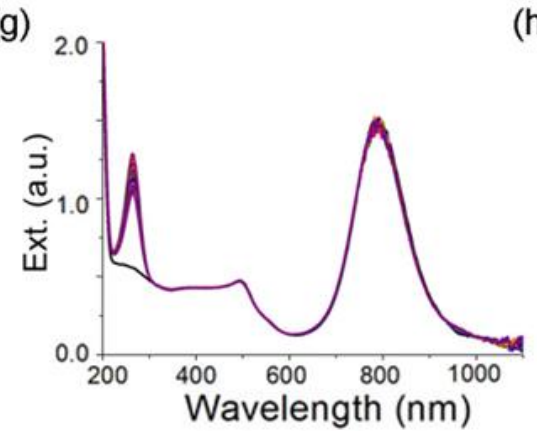

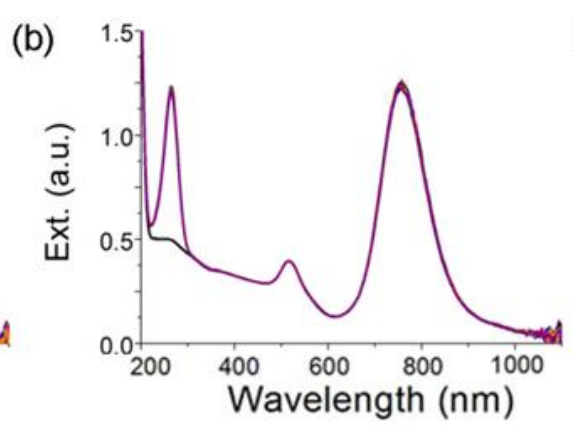

(e)

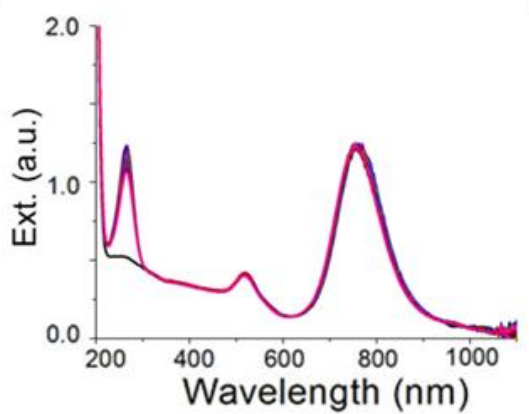

(h)

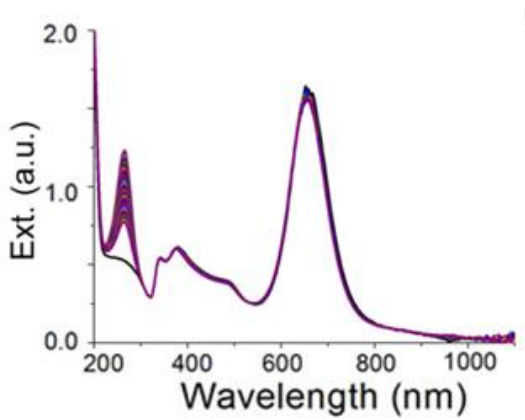

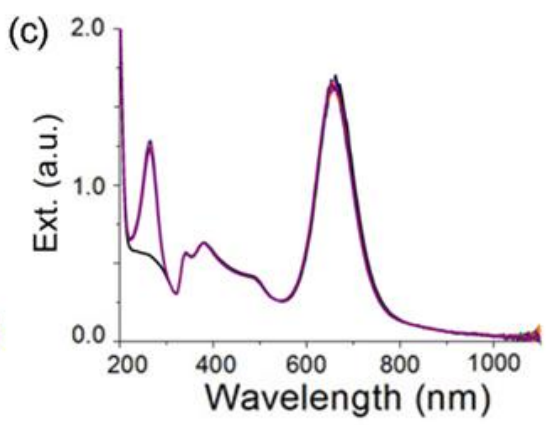

(f)

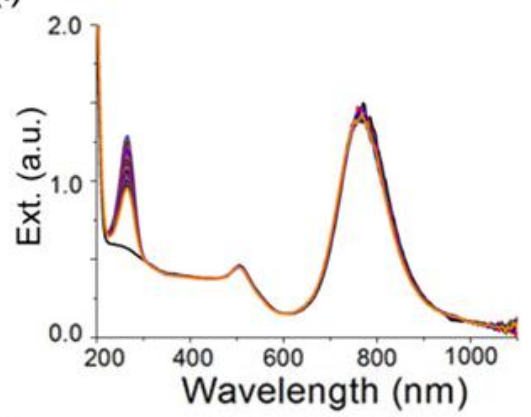

(I)

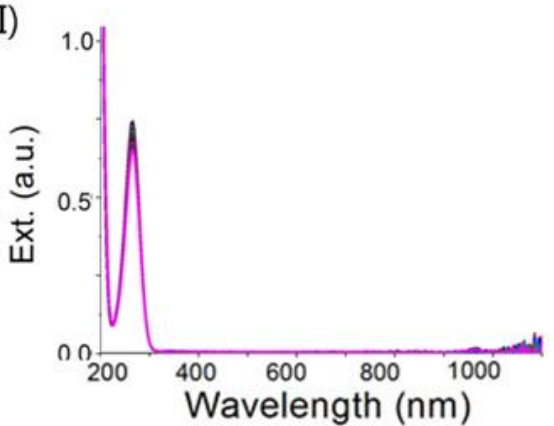

Figure S6. Extinction spectra evolution during NaA oxidation by dissolved oxygen: (a) without NRs, with (b) Au@Au, (c) Au@Ag, and (d) Au@Pt at 30 C , with (e) Au@Au, (f) Au@Aus Ag, (g) Au@Au2Agr, (h) Au@Ag and (I) without NRs at 65 C. ([Au@Au, $\left.\left.\mathrm{Au}_{3} \mathrm{Ag}, \mathrm{Au}_{2} \mathrm{Ag}_{2}, \mathrm{Ag}\right]=0.1 \mathrm{nM},[\mathrm{Au} @ \mathrm{Pt}]=0.01 \mathrm{nM},[\mathrm{CTAB}]=0.1 \mathrm{mM},[\mathrm{NaA}]=50 \mu \mathrm{M}\right)$

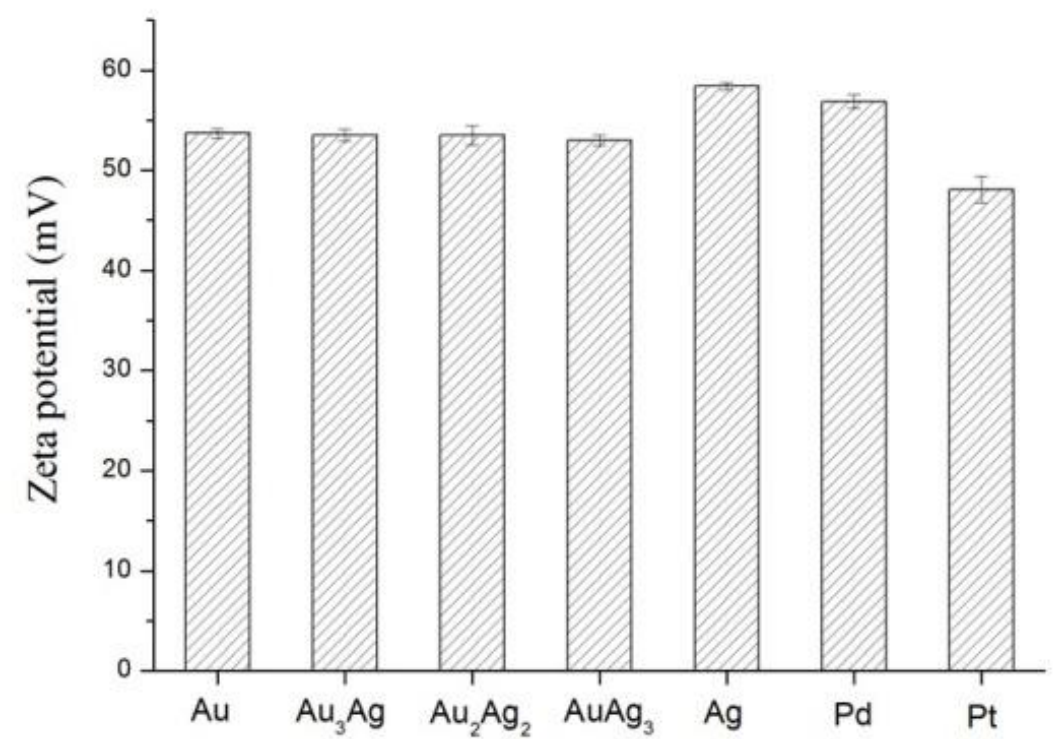

Figure S7. Zeta potentials of $0.1 \mathrm{nM}$ Au@M NRs dispersed in $0.1 \mathrm{mM}$ cetyltrimethylammonium bromide (CTAB) aqueous solutions. 

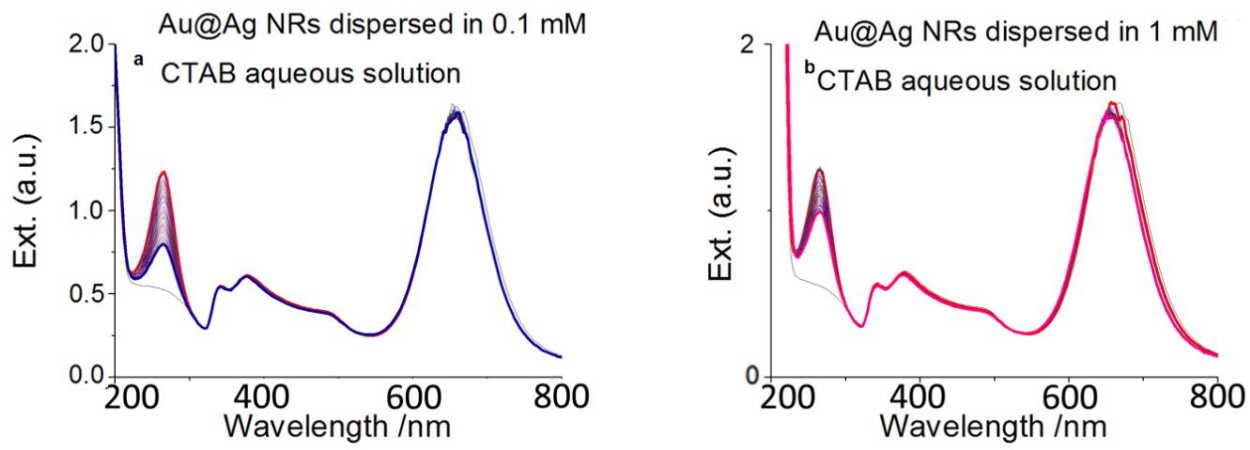

Figure S8. Effect of CTAB concentration on NaA oxidation in the case of Au@Ag1 NRs.
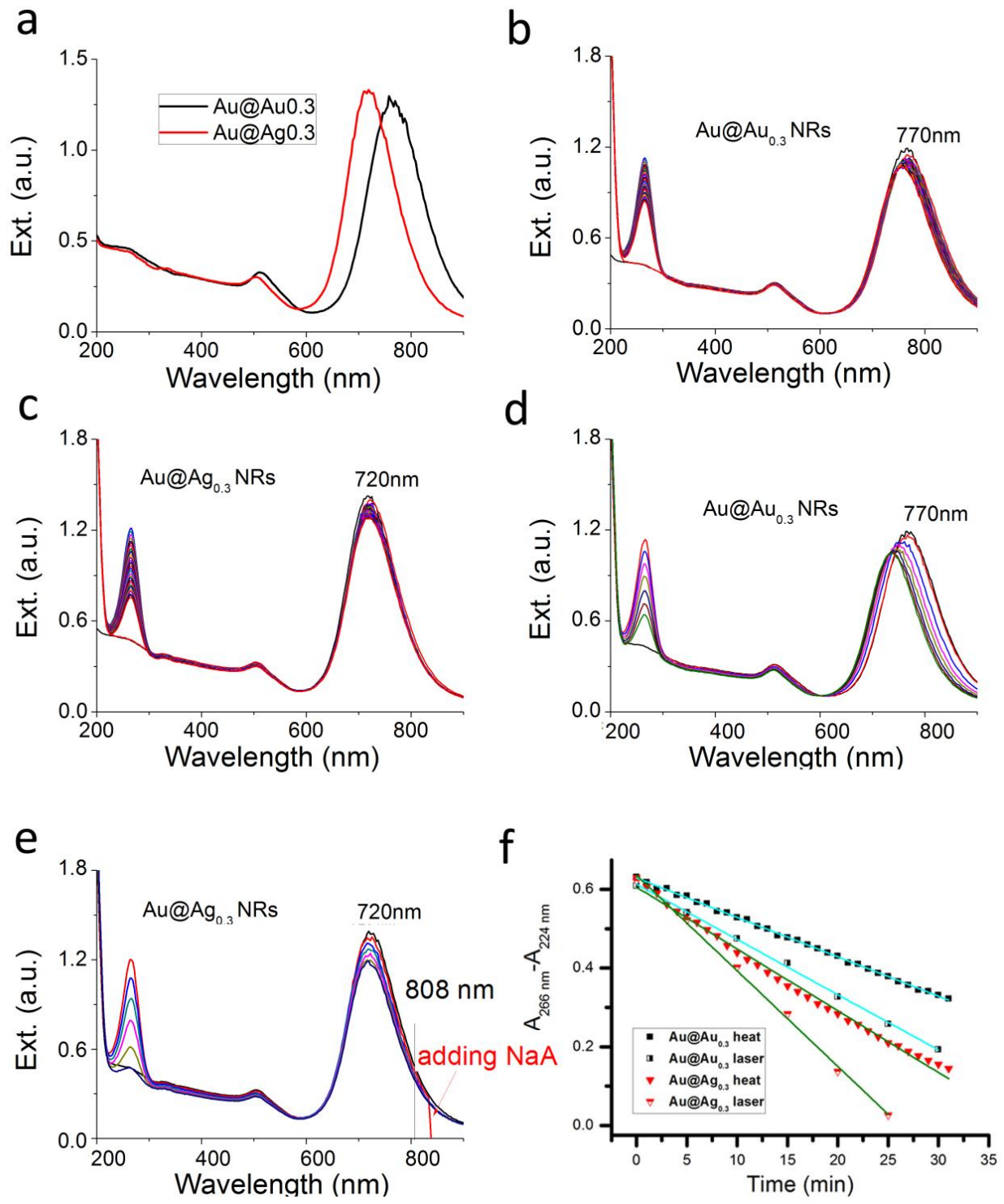

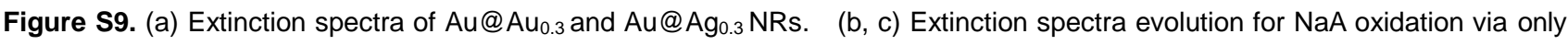
thermal activation by heating at $65^{\circ} \mathrm{C}$. $(\mathrm{d}, \mathrm{e})$ Extinction spectra evolution for $\mathrm{NaA}$ oxidation via thermal activation by heating at $65^{\circ} \mathrm{C}$ further assisted with the help of $808 \mathrm{~nm}$ laser irradiation; for laser irradiation samples, reaction temperature was adjusted to $65^{\circ} \mathrm{C}$ via heating reaction solution. (f) Enhanced $\mathrm{NaA}$ oxidation upon plasmon excitation. 


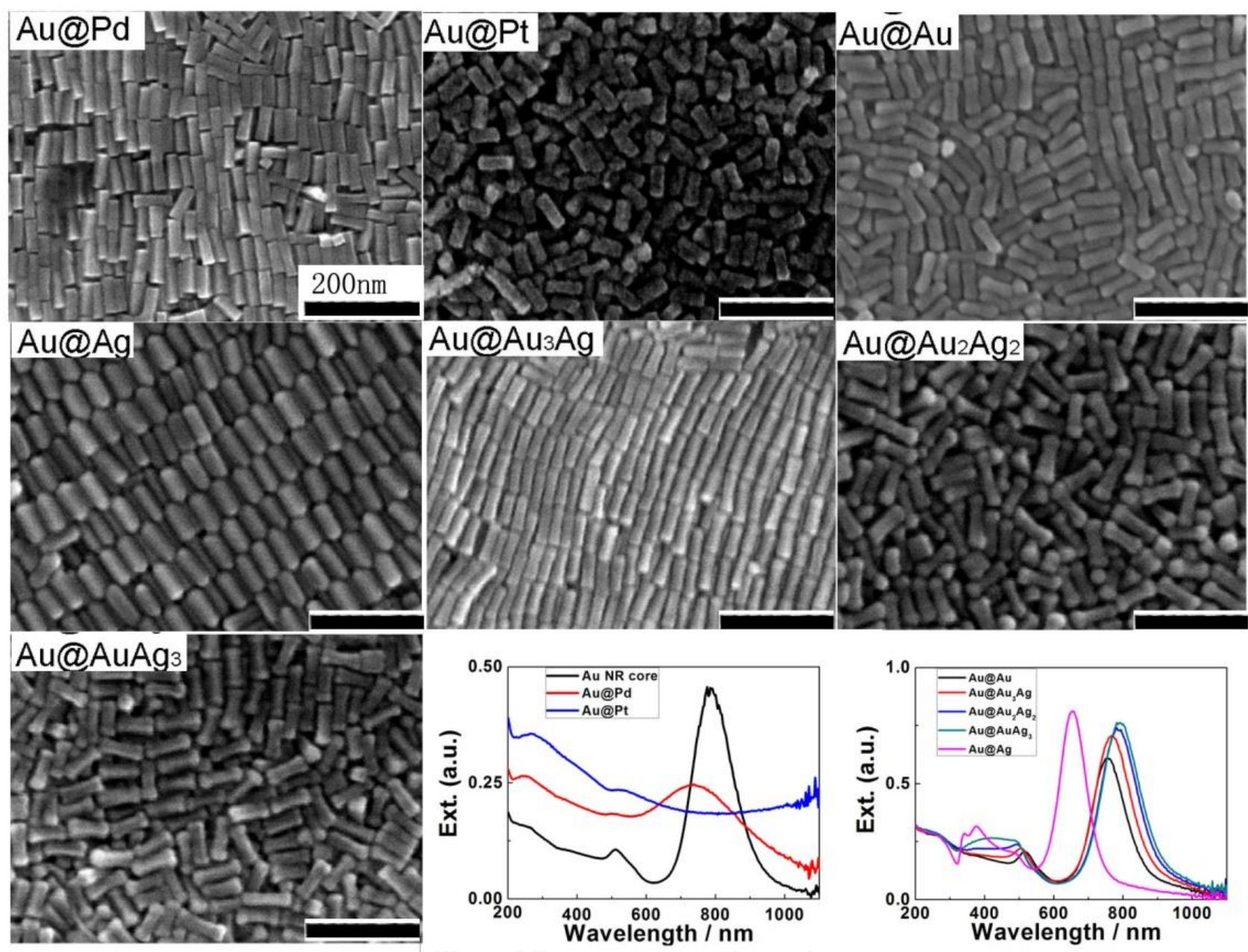

Figure S10. Typical scanning electron microscopy (SEM) images and extinction spectra of Au@M nanostructures.

Table S7 NaA Oxidation Rates by Pure Thermal Activation and Thermal plus Laser Activation

\begin{tabular}{|l|l|l|}
\hline & $A u @ A u_{0.3}$ & $A u @ A_{0.3}$ \\
\hline rate1 $\left(65^{\circ}\right)$ & $0.01 \min ^{-1}\left(R^{2}=0.9987\right)$ & $0.0157 \mathrm{~min}^{-1}\left(R^{2}=0.9930\right)$ \\
\hline rate $\left(65^{\circ}+\right.$ laser $)$ & $0.0146 \mathrm{~min}^{-1}\left(\mathrm{R}^{2}=0.9992\right)$ & $0.0256 \mathrm{~min}^{-1}\left(\mathrm{R}^{2}=0.9907\right)$ \\
\hline rate 2 / rate 1 & 1.46 & 1.64 \\
\hline
\end{tabular}


Part 8. Potential Energy Surface for $\mathrm{O}_{2}$ Adsorption and Dissociation on $\mathrm{Pd}(100)$ Facet.

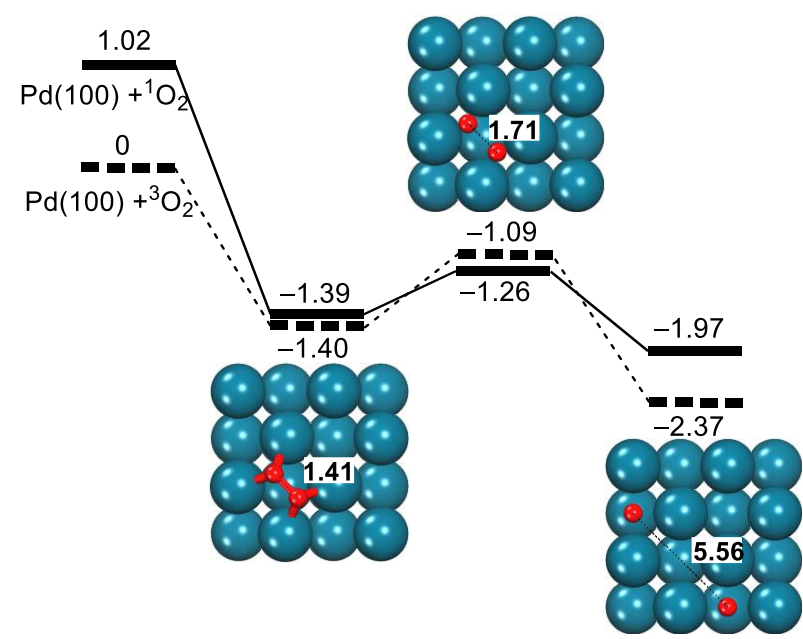

Figure S11. 2D potential energy surface for $\mathrm{O}_{2}$ adsorption and dissociation on facets of $\mathrm{Pd}(100)$. The solid and dashed lines are low- and high-spin results, respectively. Relative energies (in eV) and O-O atomic distances (in $\AA$ ) are marked.

\section{Part 9. Energies of Optimized Structures.}

Table S8. Total Energies (unit: hartree) of the Initial Structures (IS), Transition State (TS), and Final Structures (FS) for ${ }^{3} \mathrm{O}_{2}$ Dissociative Adsorption on Pure Metal Surfaces ${ }^{a}$

\begin{tabular}{cccc}
\hline & IS & TS & FS \\
\hline $\mathrm{Pd}(111)$ & -6.870 & -6.846 & -6.920 \\
$\mathrm{Pt}(111)$ & -8.022 & -7.990 & -8.069 \\
$\mathrm{Ag}(111)$ & -3.900 & -3.848 & -3.894 \\
$\mathrm{Au}(111)$ & -4.487 & -4.410 & -4.462 \\
$\mathrm{Au}(110)$ & -4.050 & -3.983 & -4.045 \\
$\mathrm{Au}(211)$ & -4.717 & -4.687 & -4.719
\end{tabular}

aUsing the spin-polarized PBE functional.

Table S9. Total Energies (unit: hartree) of the Initial Structures (IS), Transition State (TS), and Final Structures (FS) for ${ }^{1} \mathrm{O}_{2}$ Dissociative Adsorption on Pure Metal Surfaces ${ }^{a}$

\begin{tabular}{cccc}
\hline & IS & TS & FS \\
\hline $\mathrm{Pd}(111)$ & -6.867 & -6.845 & -6.917 \\
$\mathrm{Pt}(111)$ & -8.019 & -7.990 & -8.068 \\
$\mathrm{Ag}(111)$ & -3.886 & -3.848 & -3.894 \\
$\mathrm{Au}(111)$ & -4.460 & -4.408 & -4.454 \\
$\mathrm{Au}(110)$ & -4.042 & -3.983 & -3.993 \\
$\mathrm{Au}(211)$ & -4.694 & -4.688 & -4.699 \\
\hline
\end{tabular}

a Using the spin-unpolarized PBE functional. 
Table S10. Total Energies (unit: hartree) of the Initial Structures (IS), Transition State (TS), and Final Structures (FS) for ${ }^{3} \mathrm{O}_{2}$ Dissociative Adsorption on Alloy Surfaces ${ }^{a}$

\begin{tabular}{lccc}
\hline & IS & TS & FS \\
\hline $\mathrm{Au}_{3} \mathrm{Pd}(111)$ & -6.723 & -6.694 & -6.770 \\
$\mathrm{Au}_{2} \mathrm{Pd}_{2}(111)$ & -10.101 & -10.037 & -10.073 \\
$\mathrm{AuPd}_{3}(111)$ & -11.206 & -11.144 & -11.186 \\
$\mathrm{Au}_{3} \mathrm{Pt}(111)$ & -9.121 & -9.067 & -9.114 \\
$\mathrm{Au}_{2} \mathrm{Pt}_{2}(111)$ & -10.729 & -10.685 & -10.700 \\
$\mathrm{AuPt}_{3}(111)$ & -12.400 & -12.364 & -12.411 \\
$\mathrm{Au}_{3} \mathrm{Ag}_{(111)}$ & -7.209 & -7.173 & -7.260 \\
$\mathrm{Au}_{2} \mathrm{Ag}_{2}(111)$ & -7.007 & -6.965 & -7.042 \\
$\mathrm{AuAg}_{3}(111)$ & -6.723 & -6.694 & -6.770 \\
\hline
\end{tabular}

aUsing the spin-polarized PBE functional.

Table S11. Total Energies (unit: hartree) of the Initial Structures (IS), Transition State (TS), and Final Structures (FS) for ${ }^{1} \mathrm{O}_{2}$ Dissociative Adsorption on Alloy Surfaces ${ }^{a}$

\begin{tabular}{lccc}
\hline & $\mathrm{IS}$ & $\mathrm{TS}$ & $\mathrm{FS}$ \\
\hline $\mathrm{Au}_{3} \mathrm{Pd}(111)$ & -8.859 & -8.805 & -8.848 \\
$\mathrm{Au}_{2} \mathrm{Pd}_{2}(111)$ & -10.101 & -10.040 & -10.084 \\
$\mathrm{AuPd}_{3}(111)$ & -11.173 & -11.116 & -11.170 \\
$\mathrm{Au}_{3} \mathrm{Pt}(111)$ & -9.105 & -9.067 & -9.111 \\
$\mathrm{Au}_{2} \mathrm{Pt}_{2}(111)$ & -10.730 & -10.686 & -10.700 \\
$\mathrm{AuPt}_{3}(111)$ & -12.399 & -12.359 & -12.411 \\
$\mathrm{Au}_{3} \mathrm{Ag}(111)$ & -7.207 & -7.173 & -7.245 \\
$\mathrm{Au}_{2} \mathrm{Ag}_{2}(111)$ & -7.007 & -6.973 & -7.045 \\
$\mathrm{AuAg}_{3}(111)$ & -6.730 & -6.701 & -6.770 \\
\hline
\end{tabular}

${ }^{a}$ Using the spin-unpolarized PBE functional. 